\title{
A long-term baby mix-up case in the Eastern Mediterranean region
}

\author{
A. Tug and H.D. Ozguven ${ }^{2}$
}

\section{Introduction}

The movie "La vie est un long fleuve tranquille" tells the story of events starting with the attempt of a nurse to hurt the physician she works for by switching 2 babies he helped deliver, ending with the truth surfacing 12 years later. Baby mix-ups are not only material for an interesting movie plot, it also happens in real life. According to the Tanderberg annual report 1998, 1 out of 8 babies born in US hospitals are delivered to the wrong parents [1].

Baby mix-ups can occur in a number of ways. A baby may be deliberately switched with another, for example in societies where girls are socially less desirable and giving birth to a boy is important to preserve the marriage union, a baby girl may be switched with a baby boy [2]. However, hospitals usually notice the exchange of babies of a different sex and resolve the matter in a relatively short period of time. Secondly, babies may be involuntarily separated from their families during a natural disaster and be cared for by another family. In this case, relatives may claim the child on the basis of physical resemblance. One of the best known cases is baby number 81 , one of nearly 1000 babies that became orphaned in the wake of the tsunami earthquake in South Asia in 2004. Through a public address officials tried to locate the parents of the baby. Nine couples responded claiming they were the parents. In fact, one of the couples was arrested during an attempt to abduct the baby from the hospital. A DNA test enabled the baby to be returned to its biological parents. The third instance is when, due to the negligence of hospital staff, babies are handed over to the wrong family after delivery. Baby mix-ups caused by hospital staff negligence are usually reversed in a few days in most cases. However, in big hospitals without any reliable ID recording system the baby mix-up may not be noticed for a long time, until the mother, father or child become suspicious and make an inquiry.

These traumatic events in the life of parents and child are underreported in the literature, because they go unnoticed or are corrected by the hospital in the first few days after the mix-up. The psychological and social dimensions of the event have not been explored adequately. This report of a baby mixup case in the Eastern Mediterranean region aims to contribute to the literature in this field. We report on the case of 2 boys - one Turkish, one Saudi Arabian-delivered at a private hospital in 2003 and given to the wrong parents, a fact which was not discovered until 4 years later.

\section{Case report}

In May 2007 a Turkish couple presented to the forensic DNA research laboratory at the University of Ankara Faculty of Medicine in Turkey for DNA testing. They were suspicious that they were not the biological parents of their child, who was born in a Saudi Arabian hospital in 2003.

According to the statement of the father, although at first sight the child's skin colour caught their attention, the possibility of a mix-up in the Saudi Arabian hospital did not cross their mind. The family had returned to Turkey and raised the child in line with Turkish traditions and customs. However, the child's physical appearance started to be noticed by their family and social circle and the parents were often confronted with questions as to why the child did not look like them. They decided to undergo a DNA test to overcome the psychological pressures.

We analysed 16 gene regions isolated from blood samples taken from the mother, father and child. Mismatch in at least 2 of these gene regions would be interpreted as the child not descending from them [3]. There was no match in 12 of the 16 gene regions; in other words, no blood relation existed between the child and the parents.

The family returned to the hospital in Saudi Arabia to find their biological child. The Ministry of Health of Turkey, the Turkish Embassy in Saudi Arabia, the Ministry of Health of Saudi Arabia and the Governor of Najran city in Saudi Arabia were involved, along with wide press coverage.

The Turkish family was contacted by us several times about the latest developments in this case. They reported that the management of the private hospital 
had reviewed the birth records and investigated mothers who had delivered on the same day and had contacted one of them. However, the Saudi Arabian family at first did not accept the situation and refused to take the DNA test. Finally, the Emir of Najran convinced them to take the test. The Crown Prince of Saudi Arabia confirmed the mix-up in a press conference.

At the time of writing, the families are preparing to switch the children they had been raising for 4 years. Both families announced they would sue the hospital for pecuniary and nonpecuniary compensation. Based on our contact with the Turkish family and on instructions from the King of Saudi Arabia, a team of psychologists was tasked by the Ministry of Health with visiting the families and providing consultation on how to explain the situation to the children. Moreover, the families now live in adjoining houses so as to be close to both children.

\section{Discussion}

With a few exceptions, the birth of a child is one of the happiest moments in the life of parents. However, suspicion soon after the birth or even many years later that they might not be the biological parents is devastating to a family. Even if the truth eventually emerges, it is obvious that the experience leaves indelible marks on the life of families.

When suspicions about paternity are raised on the basis of the appearance of the child, a mix-up at the hospital is not always the first possibility crossing their mind. The husband struggles with the suspicion that his wife might have had an extramarital sexual relationship. This may even end with physical violence to the woman. In our case, the father reported that comments about the lack of resemblance between him and the child put him under increasing pressure and led to feelings of alienation from the his wife and child. As for the woman's point of view, she regarded her husband's request for DNA test as proof of his distrust in her. In this case, the mother wanted to "clear herself" in the face of increasing social pressure and to provide evidence to those who doubted the paternity of the child.

When a mix-up is discovered many years later, families find it difficult to adapt to the new situation. There is bereavement associated with separating from a child that was raised as one's own. Clearly what makes a man and a woman into parents is the relationship and attachment with the child rather than the biological link between them. The attachment between parents and an adopted child is of the same quality as the attachment between parents and their biological child [4]. Separation after development of an attachment results in severe grief/bereavement. Nevertheless, having overcome the first shock of the situation, adults are capable of developing coping solutions. For the child there may be more difficulties and more time may be needed to adapt to the new circumstances.

Although the parents had exerted great efforts to find out the truth, the outcome was clearly distressing. In our case, the Turkish father said that he was distraught to learn the truth and he cried often. Rather than being happy about reuniting with their biological child, they were grieved to lose the child they had been raising for 4 years and were attached to. The 4-year-old child had more serious adaptation issues. Seeing its own photograph next to a photograph of a stranger in the newspaper he asked questions. The Turkish family responded simply by saying that he now had 2 mothers and 2 fathers. However, according to the father, the child kept on saying that he was a Turk and did not want any second mother or father. He was crying constantly, afraid of being given away to "strangers". The child said he missed his Turkish relatives and complained about headaches. It is not difficult to imagine that the Saudi Arabian family had similar problems. The Saudi Arabian family did not consent to the DNA test at first and had a more difficult time accepting the truth. The Saudi Arabian father expressed emotional devastation on learning about the result. He believed the child they raised was their own and initially denied that they could separate from him.

The parties involved and their families and communities needed to act with a high level of awareness to recover from this event with minimum damage. In this case the child was old enough to be aware of what was going on and to remember the early years of life, yet still too young to make sense of the situation and cope easily with starting a new life with a new family whose language he did not speak. The term "biological parents" does not mean a lot to a child. It wants to spend its life with people whom it loves and trusts and who have been around from birth onwards. If a psychological evaluation concludes that transferring the custody to the biological parents would have grave consequences, the request to switch children could be rejected and both families granted the right to visit their biological child whenever they wished to do so.

The meaning of biology within the concept of "becoming a family" can be questioned. Although the Turkish family thought the Saudi Arabian child did not look like them and could not be theirs, the attachment to it was too deep to let him go even after having found their biological child. The fact that the Saudi Arabian family were also not willing to give up the Turkish child, despite the DNA test result showing no blood ties, makes us understand that genetics do not define a family. It is also understandable that families discovering the existence of a biological child want to be reunited with it, without taking account of the associated problems or in the belief they can overcome them. For this transition period to be less traumatic, the families should receive professional 
care from a psychologist. The child needs to have the truth explained under the supervision of experts and to understand that it will continue to see the family it was raised by after meeting its biological parents. It is important that both families establish close ties with each other and continue contact with the children they raised. Saudi Arabian officials allocating adjoining houses to the families have made a correct decision in this regard.

In addition to a very difficult period for the families after discovery of the baby mix-up, hospitals themselves may incur financial damage and loss of reputation. The Saudi Arabian family sued the hospital for 13 million US dollars. Hospitals can prevent mixups by taking careful measures. Wrist tags with the name of the mother and the baby on them may fall off, be taken off or similar names may be confused. Besides using high-technology electronic records, hospital records should be kept meticulously and the staff trained [5]. If the family suspects that their baby has been mixed up, the baby should have a DNA test as soon as possible. If babies are mixed up and breastfed by the non-biological mother, they should also be tested for HIV and hepatitis C, since these viruses can be transmitted through breastfeeding $[6,7]$.

Dismissing baby mix-ups as human error is an underestimation of the many dimensions of the phenomenon. As this case clearly demonstrates, lasting suspicions of marital infidelity can gnaw on a family. If a DNA test is carried out and confirms the mix-up, an even more difficult period of adaptation starts for the children and the families. Such severely traumatic incidents can be prevented if the families are attentive and hospitals take the necessary measures to prevent errors.

\section{References}

1. Mother of switched baby sues for $\$ 37 M$ (http://www.washingtonpost.com/wp-srv/local/daily/may99/baby25.htm, accessed 12 January 2010).

2. Turney L et al. DNA paternity testing: Public perceptions and the influence of gender. Australian Journal of Emerging Technologies and Society, 2003, 1(1):21-37.

3. Bringmann B, Möller A, Wiegand P. Structure of new mutations in 2 STR systems. International Journal of Legal Medicine, 1995, 107:201-203.

4. Howe D. Age at placement, adoption experience and adult adopted people's contact with their adoptive and birth moth- ers: an attachment perspective. Attachment and Human Development, 2001, 3(2):222-237.

5. Crane TR. Mistaken baby switches: an analysis of hospital liability and resulting custody issues. Journal of Legal Medicine, 2000, 21(1):109-124.

6. Lifson AR. Do alternate modes for transmission of human immunodeficiency virus exist? A review. Journal of the American Medical Association, 1988, 259:1353-1356.

7. Polywka $\mathrm{S}$ et al. Low risk of vertical transmission of hepatitis C virus by breast milk. Clinical Infectious Diseases, 1999, 29:1327-1329. 